\title{
Gamma and Delta Neural Oscillations and Association with Clinical Symptoms under Subanesthetic Ketamine
}

\author{
L Elliot Hong*,', Ann Summerfelt', Robert W Buchanan', Patricio O'DonnelI ${ }^{2}$, Gunvant K Thaker', \\ Martin A Weiler' and Adrienne C Lahti ${ }^{1,3}$ \\ 'Department of Psychiatry, Maryland Psychiatric Research Center, University of Maryland School of Medicine, Baltimore, MD, USA; ${ }^{2}$ Department \\ of Anatomy and Neurobiology and Psychiatry, University of Maryland School of Medicine, Baltimore, MD, USA; ${ }^{3}$ Department of Psychiatry and \\ Behavioral Neurobiology, University of Alabama at Birmingham, Birmingham, AL, USA
}

\begin{abstract}
Several electrical neural oscillatory abnormalities have been associated with schizophrenia, although the underlying mechanisms of these oscillatory problems are unclear. Animal studies suggest that one of the key mechanisms of neural oscillations is through glutamatergic regulation; therefore, neural oscillations may provide a valuable animal-clinical interface on studying glutamatergic dysfunction in schizophrenia. To identify glutamatergic control of neural oscillation relevant to human subjects, we studied the effects of ketamine, an $\mathrm{N}$-methyl-D-aspartate antagonist that can mimic some clinical aspects of schizophrenia, on auditory-evoked neural oscillations using a paired-click paradigm. This was a double-blind, placebo-controlled, crossover study of ketamine vs saline infusion on 10 healthy subjects. Clinically, infusion of ketamine in subanesthetic dose significantly increased thought disorder, withdrawal-retardation, and dissociative symptoms. Ketamine significantly augmented high-frequency oscillations (gamma band at $40-85 \mathrm{~Hz}, p=0.006$ ) and reduced lowfrequency oscillations (delta band at $\mathrm{I}-5 \mathrm{~Hz}, \mathrm{p}<0.00 \mathrm{I}$ ) compared with placebo. Importantly, the combined effect of increased gamma and reduced delta frequency oscillations was significantly associated with more withdrawal-retardation symptoms experienced during ketamine administration $(p=0.02)$. Ketamine also reduced gating of the theta-alpha $(5-12 \mathrm{~Hz})$ range oscillation, an effect that mimics previously described deficits in schizophrenia patients and their first-degree relatives. In conclusion, acute ketamine appeared to mimic some aspects of neural oscillatory deficits in schizophrenia, and showed an opposite effect on scalp-recorded gamma vs low-frequency oscillations. These electrical oscillatory indexes of subanesthetic ketamine can be potentially used to cross-examine glutamatergic pharmacological effects in translational animal and human studies.

Neuropsychopharmacology (2010) 35, 632-640; doi: I 0.1038/npp.2009.168; published online 4 November 2009
\end{abstract}

Keywords: NMDA; GABA; glutamate; negative symptom; schizophrenia; sensory gating

\section{INTRODUCTION}

Several electrical neural oscillatory abnormalities have been associated with schizophrenia. Many studies have focused on the gamma band, and in general identified gamma reduction in power or phase in schizophrenia (Kwon et al, 1999; Kissler et al, 2000; Lee et al, 2001; Gallinat et al, 2004; Symond et al, 2005; Cho et al, 2006). However, contrasting findings of increased gamma activities in schizophrenia also exist (Basar-Eroglu et al, 2007; Norra et al, 2004; Flynn et al, 2008). Abnormalities in lower frequency oscillations are even more prominent. Augmented low-frequency oscillations are observed in unmedicated, first-episode, and

*Correspondence: Dr Hong, Department of Psychiatry, Maryland Psychiatric Research Center, University of Maryland School of Medicine, PO Box 21247, Baltimore, MD 21228, USA, Tel: + 1410 402 6828, Fax: + I 410402 6023, E-mail: ehong@mprc.umaryland.edu Received 17 August 2009; revised 16 September 2009; accepted 17 September 2009 chronic schizophrenia patients (Clementz et al, 1994; Omori et al, 1995; Karson et al, 1988; Sponheim et al, 1994, 2003; Knott $e t$ al, 2001). A failure to suppress theta-alpha ( $\sim 5$ to $11 \mathrm{~Hz}$ ) activities during sensory gating significantly marks the genetic liability for schizophrenia (Hong et al, 2008b). However, negative and opposite findings also exist (Nagase et al, 1992; Tauscher et al, 1998; Keshavan et al, 1998). The underlying mechanisms of these abnormal clinical findings at gamma and low frequencies remain elusive.

On the other hand, mechanisms of neural oscillations have been extensively studied in animals. Neural oscillations may provide a needed bioassay platform for elucidating cellular and molecular mechanisms of human brain diseases, especially when we can draw parallels between oscillatory patterns of humans and animals. Scalp-recorded electrical oscillations are considered to be summations of local field potentials that are primarily originating from excitatory and inhibitory postsynaptic potentials, while the latter is closely related to glutamatergic and GABAergic mechanisms, respectively. It is therefore not surprising that 
current theories on neural oscillations focus on glutamatergic (Cunningham et al, 2006; Roopun et al, 2008) and GABAergic mechanisms (Whittington et al, 1995; Traub et al, 1999; Gonzalez-Burgos and Lewis, 2008).

This study focuses on the glutamatergic effects on oscillations in humans. Ketamine is a noncompetitive $N$-methyl-D-aspartate (NMDA) receptor antagonist. In subanesthetic dose, it mimics some features of schizophrenia and is often used as a pharmacological model for the NMDA hypofunction (Lahti and Tamminga, 1999; Heresco-Levy and Javitt, 1998; Meador-Woodruff and Healy, 2000; Coyle, 1996; Krystal et al, 1999). We examined ketamine-induced oscillatory responses during auditory paired-click sensory gating in normal controls using a discrete wavelet method and compared these ketamineinduced oscillatory responses to those seen in schizophrenia patients (Hong et al, 2008b). The wavelet method was believed to be sensitive for extracting single-trial-based oscillatory activities (Hong et al, 2008a).

Most previous studies of ketamine effects on sensory gating have found no significant effect of ketamine based on averaged evoked potentials (AEPs) in humans (van Berckel et al, 1998; Oranje et al, 2002) or animals (de Bruin et al, 1999). However, ketamine has shown to impair gating of responses to repeated clicks presented at $100 \mathrm{~ms}$ intervals (Boeijinga et al, 2007) and reduce AEP response to the first click in rodents (Amann et al, 2009). The endogenous NMDA antagonist kynurenic acid also disrupts AEP N40 sensory gating (Shepard et al, 2003).

AEP-based sensory gating findings in schizophrenia are somewhat mixed, with most studies showing a deficit (Siegel et al, 1984; Clementz et al, 1998; Myles-Worsley, 2002; Sanchez-Morla et al, 2008), while some are negative (Kathmann and Engel, 1990; Arnfred et al, 2003; de Wilde et al, 2007). Gating of evoked oscillations in theta-alpha range could have more robust group differences (Hong et al, 2008b; Brockhaus-Dumke et al, 2008). Therefore, our study focused on the effect of ketamine on single-trial-based oscillatory responses. We aimed to determine whether the effect of ketamine on neural oscillations in healthy humans resembles oscillations observed in NMDA animal models and oscillatory problems associated with schizophrenia patients, potentially providing a glutamatergic account on the part of the oscillatory problems found in schizophrenia patients that may index glutamatergic abnormalities.

\section{PATIENTS AND METHODS}

\section{Laboratory Procedure}

A total of 10 healthy subjects (aged $34.5 \pm 11.7$ years, 4 females) participated in a double-blind, placebo-controlled, crossover study of bonus intravenous $0.3 \mathrm{mg} / \mathrm{kg}$ ketamine or saline placebo while double-click testing was administered. Subjects were 21-55 years of age, with no history of psychiatric illnesses. All subjects gave written informed consent in accordance with the University of Maryland Institutional Review Board guidelines. Subjects received pretreatment double-click event-related potential (ERP) testing, and then received ketamine (or placebo) in a 1 -min infusion, followed immediately by $20 \mathrm{~min}$ of post-treatment ERP testing. This was repeated after 1 week with the placebo (or ketamine) administration. The drug order was considered not randomized in this study because of a miscommunication with nursing staff for the order of intravenous administration in a few cases, where the randomization table was not followed (six received placebo first and four ketamine first); although all clinical ratings by a psychiatrist were given double-blinded to the drug conditions. All data were processed under the blinded condition. Clinical interviews included the 20-item Brief Psychiatric Rating Scale (BPRS) (Hedlund and Vieweg, 1980) and the Clinician-Administered Dissociative States Scale (CADSS) (Bremner et al, 1998) immediately after each ERP testing. Following previous ketamine studies (Malhotra et al, 1996), we calculated the BPRS total score and four empirically derived factors: thought disorder, withdrawalretardation, hostility, and depressive-anxious symptom factors. The CADSS has 27 items, each scored from 0 to 4 , including 19 subject-rated items ('subjective symptoms') and 8 observer-rated items ('objective symptoms') (Bremner et al, 1998).

\section{ERP Recording}

EEGs were recorded in a sound-attenuated chamber, using a cap containing six midline tin electrodes (Electro-Cap International, Eaton, $\mathrm{OH}$ ) referenced to linked earlobes. Subjects were asked to relax with eyes open and listen to 150 pairs of click stimuli ( $1 \mathrm{~ms}$ duration, $75 \mathrm{~dB}$ amplitude, $500 \mathrm{~ms}$ interclick interval, and $10 \mathrm{~s}$ intertrial interval) delivered through a pair of loudspeakers positioned $50 \mathrm{~cm}$ away from their ears. Electrooculograms were recorded around the left eye. EEGs were sampled at $1 \mathrm{kHz}$ using a NeuroScan Synamp amplifier (Neurosoft, El Paso, TX; $200 \mathrm{~Hz}$ low pass, $1.0 \mathrm{~Hz}$ high pass) to yield $500 \mathrm{~ms}$ epochs, including a $100-\mathrm{ms}$ prestimulus window. Movement artifacts were removed from single trials with a rejection criterion of $\pm 75 \mu \mathrm{V}$ followed by visual inspection. Electrode impedance was maintained below $5 \mathrm{k} \Omega$. The central channel (CZ) was used for the P50 (Nagamoto et al, 1989; Freedman et al, 1997; Clementz et al, 1998). Data from all six channels were used for oscillatory measures.

\section{ERP Data Processing}

The single-trial records were baseline-corrected, $3-100 \mathrm{~Hz}$ (24 octave slopes) bandpass filtered, and averaged to obtain P50 waves. P50 response to the first stimulus (S1) was defined as the largest positive-going wave occurring 35-75 ms after the stimulus, measured from the trough of the preceding wave to the P50 peak. The S2 P50 was set to $\pm 10 \mathrm{~ms}$ of the latency to S1 P50 (Nagamoto et al, 1989). P50 gating was the S2/S1 P50 ratio. P50 was scored blind to drug information.

For oscillatory measures, artifact-free single trials filtered at $0.5-100 \mathrm{~Hz}$ were used. A discrete wavelet transform (DWT) approach was used. Wavelet transform of singletrial recording has the advantage of not being biased by trial-to-trial temporal variability because it extracts both stationary and nonstationary energy. There is no reason to believe that most biological or pharmacological actions use only a stationary (time-locked) mechanism. Therefore, single-trial-based analysis, by means of extracting both 
stationary and nonstationary energy, may be advantageous. The theory and methodology of using DWT to decompose evoked potential data have been examined (Hong et al, 2008a). We used an eight-level discrete biorthogonal wavelet (bio5.5, Wavelet Toolbox; MathWorks Natick, MA) to separate evoked responses into eight details (D1-D8), which represent eight frequency bands. By simulation, we estimated the frequency band of each detail: D1-D3 corresponded to very fast gamma frequency activities > $85 \mathrm{~Hz}$; D4: 40-85 Hz; D5: $20-40 \mathrm{~Hz}$; D6: $12-$ $20 \mathrm{~Hz}$; D7: $5-12 \mathrm{~Hz}$; and D8: $1-5 \mathrm{~Hz}$ (more details of the methodology are described in Hong et al, 2008a).

In previous studies using $125 \mathrm{~ms}$ epochs, we found that gating and schizophrenia patient-control differences on theta-alpha band responses are largely limited to the 25$275 \mathrm{~ms}$ post-stimulus interval (Hong et al, 2008a, b). Therefore, we elected to use a 300-ms post-stimulus epoch for oscillatory response extraction in this study. The longer epoch of $300 \mathrm{~ms}$ (as compared with the previous $125 \mathrm{~ms}$ epoch) also allowed better resolution for extracting lower frequency oscillations, especially at D8 ( $\sim 1$ to $5 \mathrm{~Hz})$. Energy within each epoch of each frequency band (detail) was measured by power spectrum density (PSD) using the nonparametric Welch method (Welch, 1967; Kay, 1988). Sensory gating of each time-frequency component was calculated as the S2 PSD/S1 PSD ratio, and averaged across all trials for each participant.

\section{Statistical Analysis}

A four-way repeated-measures ANOVA was used to compare drug (placebo vs ketamine), time (pre- and postdrug), site (FZ, FCZ, CZ, CPZ, PZ, OZ), and frequency (D1-D8) effects on oscillatory-dependent measures. Significant findings were followed by corresponding post-hoc tests. Greenhouse-Geisser corrections were applied to adjust for non-sphericity. The primary interests were effects of ketamine; therefore, post-hoc tests were carried out when there were significant interactions involving a time $\times$ drug interaction. Significant time $\times$ drug findings on frequency and/or site were followed by post-hoc paired $t$-tests to determine whether differences between ketamine and placebo were significant at the indicated frequency and/ or site. Potential effect of drug administration order was explored by examining the effect of order on time, site, and frequency. To account for potential differences at baseline (pre- and postdrug order effect), post-hoc testing also compared baseline-adjusted measures ((post-ketamine minus pre-ketamine) $v s$ (post-placebo minus pre-placebo)). Nominal significance $(p<0.05)$ and Bonferroni corrected significance after correcting for eight detail levels $(p<0.05 / 8$ $=0.00625)$ were reported. This procedure was carried out for oscillatory response to the initial auditory sensory stimulus ( $\mathrm{S} 1$ only) and sensory gating ( $\mathrm{S} 2 / \mathrm{S} 1$ ratio) separately. Oscillatory response to S2 was not separately evaluated but rather evaluated in the context of the gating ratio. AEP P50 and clinical measures were compared using two-way repeated-measures ANOVA to examine significant drug $\times$ time effects, followed by corresponding post-hoc paired $t$-tests. All tests were two-tailed. Relationships between clinical and electrophysiological measures significantly affected by ketamine were examined using either bivariate Pearson's correlations or regression analyses if more than one predictor was involved.

\section{RESULTS}

\section{Clinical Measures}

Compared with baseline and placebo, ketamine significantly increased BPRS total scores and thought disorder and withdrawal symptom factors (significant drug $\times$ time interaction), with the largest effect size on the withdrawal symptoms (Table 1). For CADSS, ketamine significantly increased the total score and the subjective symptom

Table I Effect of Subanesthetic Ketamine on Clinical Symptoms

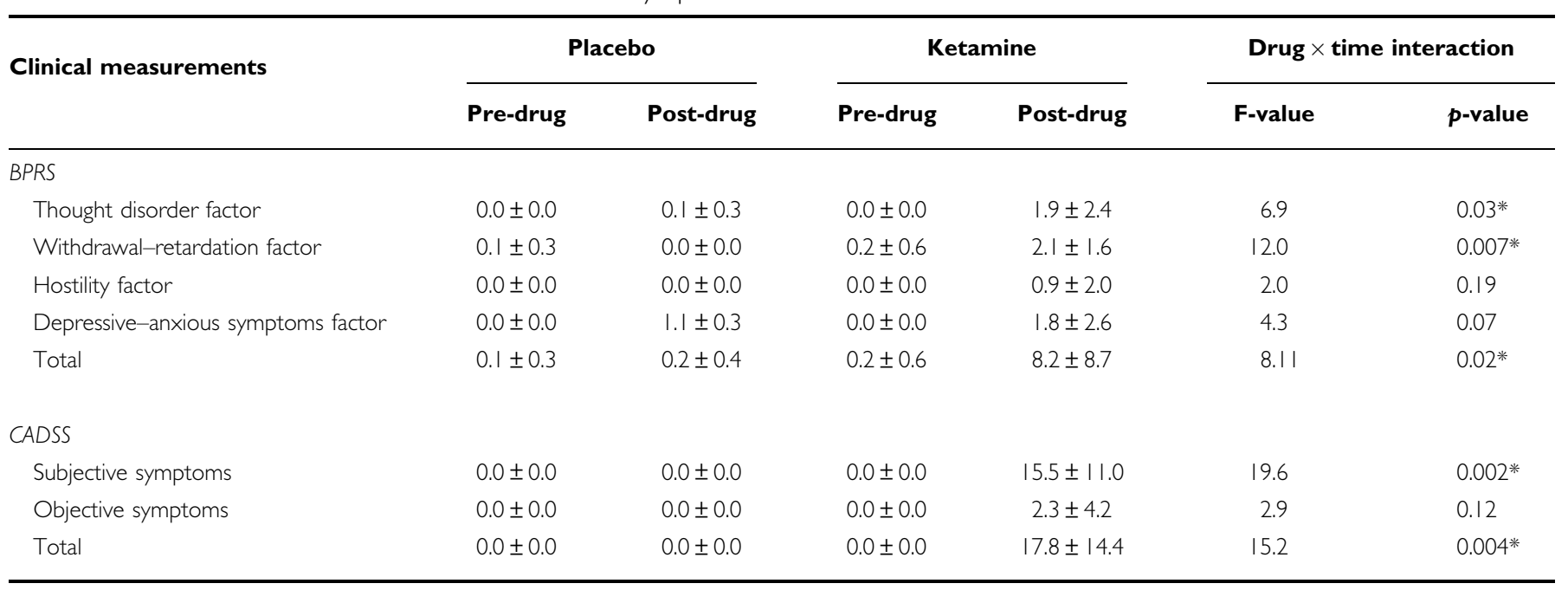

BPRS, Brief Psychiatric Rating Scale; CADSS, Clinician-Administered Dissociative States Scale.

Statistics were drug $\times$ time interactions. For BPRS, a score of I (no symptom) on an item was converted to 0 , so that sums of symptom severities in factors with different number of items are comparable.

*Statistically significant. 

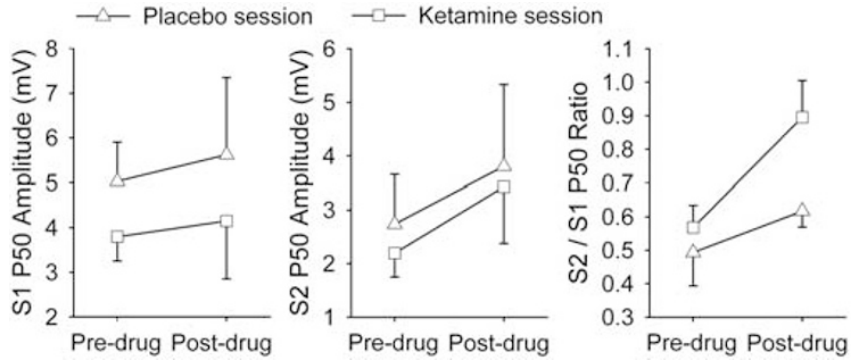

Figure I Effects of subanesthetic ketamine on P50 amplitudes and P50 ratio. There was no significant drug $\times$ time interaction in any of the measures.

subscore, but not the objective symptom subscore, compared with baseline and placebo.

\section{P50 Amplitude and Gating}

There was no significant drug $\times$ time interaction on P50 amplitudes (Figure 1). Ketamine did not significantly affect P50 gating (Figure 1, right panel; drug $\times$ time interaction $(\mathrm{F}(1,9)=1.97, p=0.19))$. Exploratory comparison showed that post-drug ketamine reduced gating compared with post-drug placebo, although this was not statistically significant $(t=2.15, p=0.06)$.

\section{Oscillatory Responses to Sensory Stimulus (S1 Single Click)}

There were significant three-way time $\times$ drug $\times$ frequency $(\mathrm{F}(2.4,19.3)=4.35, \quad p=0.02), \quad$ drug $\times$ frequency $\quad(\mathrm{F}(1.5$, $11.9)=5.70, \quad p=0.02)$, and weak evidence of site $\times$ frequency $(\mathrm{F}(2.1,17.1)=3.17, p=0.06)$ and site $(\mathrm{F}(5$, $40)=2.12, p=0.08)$ effects. Post-hoc tests showed significant drug (post-placebo vs post-ketamine) $\times$ frequency interactions at the $\mathrm{CZ}(\mathrm{F}(7,18.1)=4.87, p=0.04))$ and weak evidence of drug $\times$ frequency effects at the FCZ $(p=0.08)$ and FZ $(p=0.06)$, but not at the posterior sites (all $p>0.21$ in the CPZ, PZ, and OZ sites). Subsequent posthoc tests focused on the $\mathrm{CZ}$, although most findings from the FZ were similar (data not shown). Ketamine had an opposite effect on gamma and low-frequency bands at the CZ: ketamine increased gamma PSD (D4 or $40-85 \mathrm{~Hz}$ : $t=3.6, p=0.006$ ) and reduced low-frequency PSD (D7 or theta-alpha at 5-12 Hz: $t=-2.4, p=0.04$; D8 or delta at $1-5 \mathrm{~Hz}: t=-6.8, p<0.001)$ compared with placebo during post-drug testing (Figure 2, top). The results were similar in post-drug minus pre-drug differences (ie, adjusted for baseline) analyses: ketamine increased gamma (D4: $t=3.5$, $p=0.006)$ and reduced low-frequency power compared with placebo (D7: $t=-2.7, p=0.02$; D8: $t=-3.7, p=0.005$ ) (Figure 2, bottom). The effects on D4 (gamma) and D8 (delta), but not on D7 (theta-alpha), were significant after Bonferroni corrections. The D4 and D8 responses of each subject were plotted in Figure 3. There were no significant time $\times$ drug interactions on frequency or site when oscillatory responses to $\mathrm{S} 2$ were examined (data not shown). Finally, there were no significant effects of drug order on frequency or site.

To summarize, ketamine significantly increased gamma and reduced low-frequency oscillations in response to
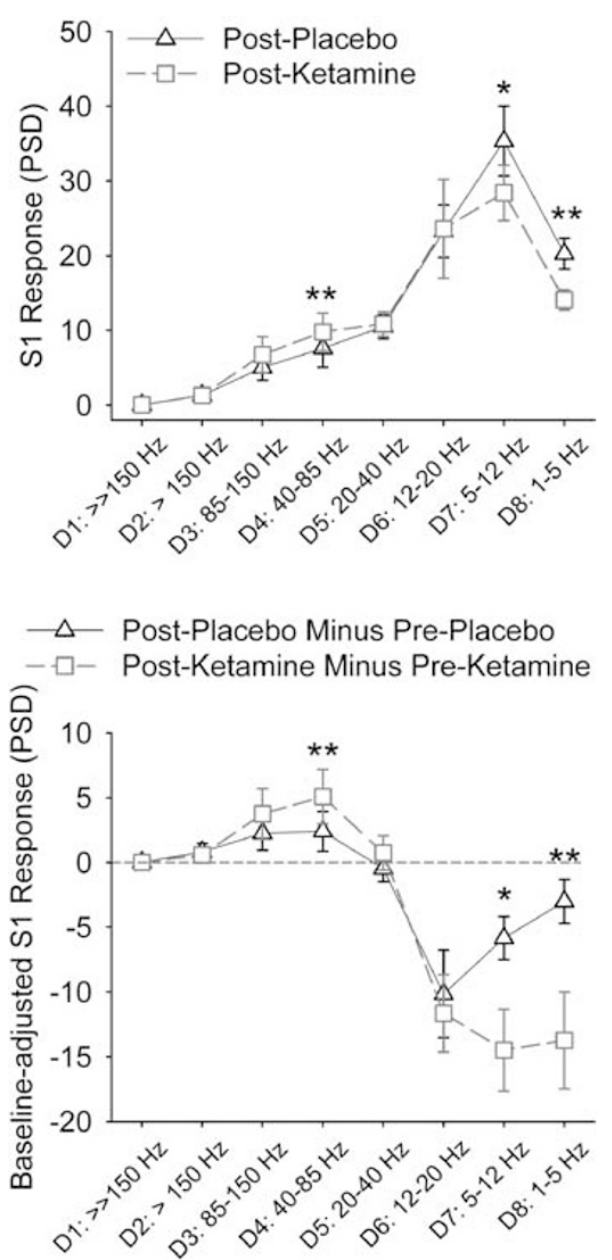

Figure 2 Post-hoc paired $t$-tests of subanesthetic ketamine effect on oscillatory responses to single auditory click (SI) at the CZ. Top: comparing the ketamine effect based on post-drug recordings, ie, post-placebo vs post-ketamine; bottom: comparing the ketamine effect after adjusting for baseline recordings. The corresponding frequency bands of the discrete wavelet details: D4: 40-85 Hz (gamma); D5: 20-40 Hz (low gamma); D6: I2-20 Hz (beta); D7: 5- $12 \mathrm{~Hz}$ (theta-alpha); and D8: I-5 Hz (delta). DID3 correspond to very fast activities $>85 \mathrm{~Hz}$ (the precise range of frequencies for detail level DI and D2 has not been formally simulated except that they represent very high and ultra high gamma. Note that frequency band $>100 \mathrm{~Hz}$ was filtered out in this experiment). *Nominally significant $p<0.05$. ** Significant after Bonferroni correction.

auditory sensory stimuli, an effect most prominently shown at the $\mathrm{CZ}$ site.

\section{Gating of Oscillatory Responses (S2/S1 Ratio)}

There were significant three-way time $\times$ drug $\times$ frequency $(\mathrm{F}(3.2,29.2)=2.29, p=0.038)$, two-way drug $\times$ frequency $(\mathrm{F}(3.4,30.8)=4.60, p=0.007)$, time $\times$ frequency $\quad(\mathrm{F}(2.4$, $22.0)=2.97, \quad p=0.03), \quad$ and site $\times$ frequency $\quad(\mathrm{F}(4.0$, $35.6)=3.36, p=0.02$ ) interactions. The three-way timedrug $\times$ frequency interaction was significant only at the $\mathrm{CZ}$ $(\mathrm{F}(3.5,31.9)=2.84, p=0.046)$ and with weak evidence for interaction at the neighboring CPZ $(p=0.09)$ and FCZ $(p=0.07)$. We again used only the CZ for post-hoc analyses. Ketamine increased the S2/S1 ratio (reduced gating) at D7 $(t=4.97, p=0.001)$ and $\mathrm{D} 8(t=2.65, p=0.03)$ compared with placebo during post-drug testing (Figure 4 top). The 

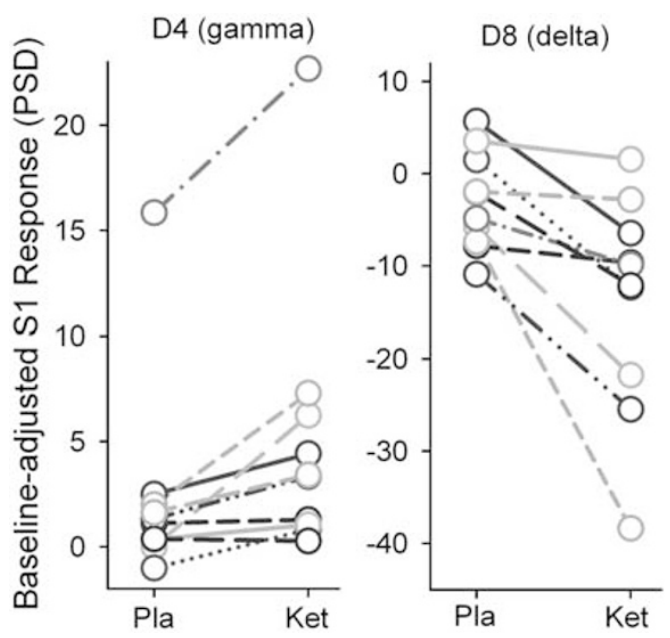

Figure 3 Plotting individual subject's oscillatory response to single click under placebo (Pla) vs subanesthetic ketamine (Ket). Most subjects showed a pattern of increased gamma and reduced delta. Data were adjusted for pre-drug baseline. One subject showed an unusually large order effect on gamma (the subject on the top of the left panel), with increased gamma in post-drug compared with pre-drug condition. Although this order effect was clearly an outlier compared with the rest of the subjects, this order effect was present in both placebo and ketamine sessions and the drug effects (ketamine minus placebo) on both gamma and delta bands were not considered outliers.

results were similar after adjusting for baseline: ketamine increased the ratio at D7 $(t=3.84, p=0.004)$ and D8 $(t=2.68, p=0.02)$ compared with placebo (Figure 4 bottom). The effect on D7 gating was significant after the Bonferroni correction.

\section{Electrophysiology - Clinical Rating Correlates}

To limit multiple comparisons, only measures significantly affected by ketamine were examined in their relationships with clinical ratings. Only clinical and electrophysiological data recorded during the ketamine infusion session were used because participants essentially have no clinical symptoms during the other three sessions (ie, little or no clinical variance, see Table 1).

To examine potential contributions of S1 oscillatory responses at D4 (gamma at CZ) and D8 (delta at CZ) and their interaction to clinical ratings, a regression model was used, in which the dependent measure was a clinical rating and the predictors were D4, D8, and their interaction term. For BPRS total and factor scores, the only significant model was with the withdrawal symptom factor (model $R^{2}$ change $=79.3 \%, \mathrm{~F}(3,9)=7.7, p=0.018)$. The $\mathrm{D} 4 \times \mathrm{D} 8$ interaction term was significant (standardized beta $=-5.7$, $t=-3.1, p=0.02$ ). Partial correlation suggested that the severity of withdrawal symptoms experienced by the subjects were positively correlated with D4 and negatively correlated with D8 (Figure 5). This finding is interesting because withdrawal symptoms also showed the most robust ketamine effect (Table 1) and a D4 $\times$ D8 interaction explained a large proportion of the withdrawal-retardation experience. We failed to find significant regression models that may explain the CADSS total or subscale scores.
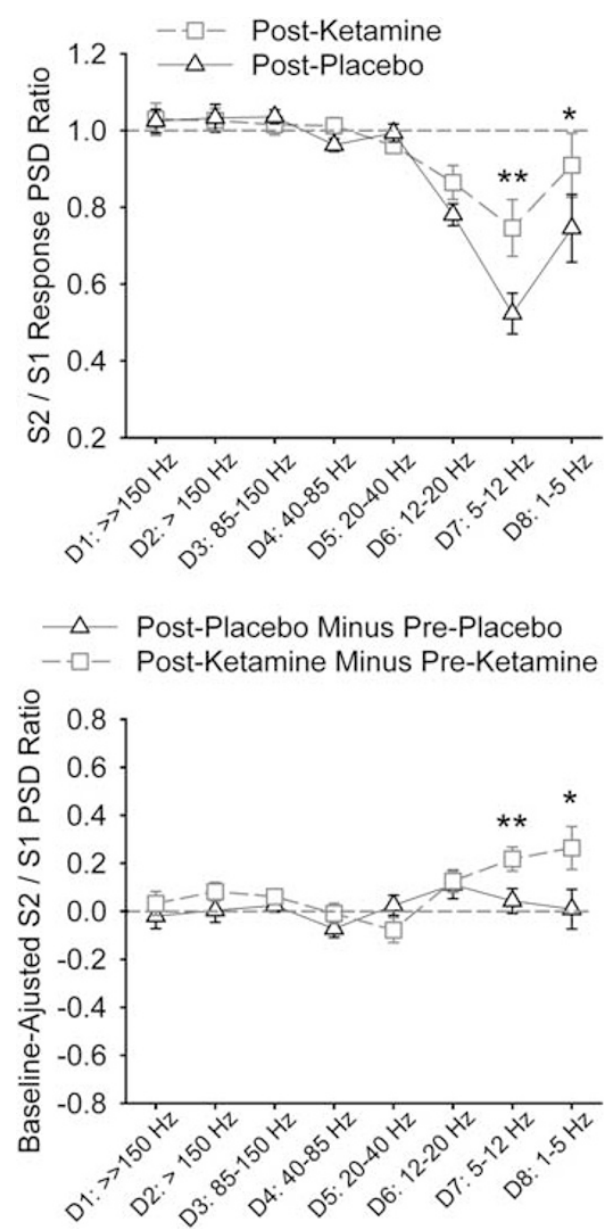

Figure 4 Post-hoc paired t-tests of the ketamine effect on gating of oscillatory responses (S2/SI ratio) at the CZ. Top: comparing the ketamine effect based on post-drug recordings, ie, post-placebo vs post-ketamine. Increases in the ratio imply worse sensory gating and vice versa. The ratio $=I$ if no gating is present. Bottom: comparing the ketamine effect after adjusting for baseline recordings. Here, value $=0$ if there is no change in gating between pre-drug (baseline) and post-drug. Increases in the ratio imply worse sensory gating and vise versa. *Nominally significant $p<0.05$. ** Significant after Bonferroni correction.

To examine the effect of $\mathrm{D} 7$ gating on clinical symptoms, Pearson's correlations were carried out between the D7 S2/ $S 1$ ratio and clinical ratings. No significant correlations were found for BPRS or CADSS.

\section{DISCUSSION}

We found that subanesthetic dose of ketamine has opposite effects on human gamma and low-frequency oscillations: ketamine augmented gamma $(40-85 \mathrm{~Hz})$ and reduced delta $(1-5 \mathrm{~Hz})$ and, to some extent, theta-alpha $(5-12 \mathrm{~Hz})$ frequency oscillations compared with placebo. This finding replicated similar protocols in mouse (Ehrlichman et al, 2009; Lazarewicz et al, 2009) and rats (Hunt et al, 2009), in which ketamine increased gamma and reduced lowfrequency oscillations, although the clinical correlates of these oscillatory effects were not clear from earlier animal studies. Subanesthetic ketamine is known to reliably increase thought disorder and withdrawal-retardation symptoms as measured by corresponding BPRS factors in 

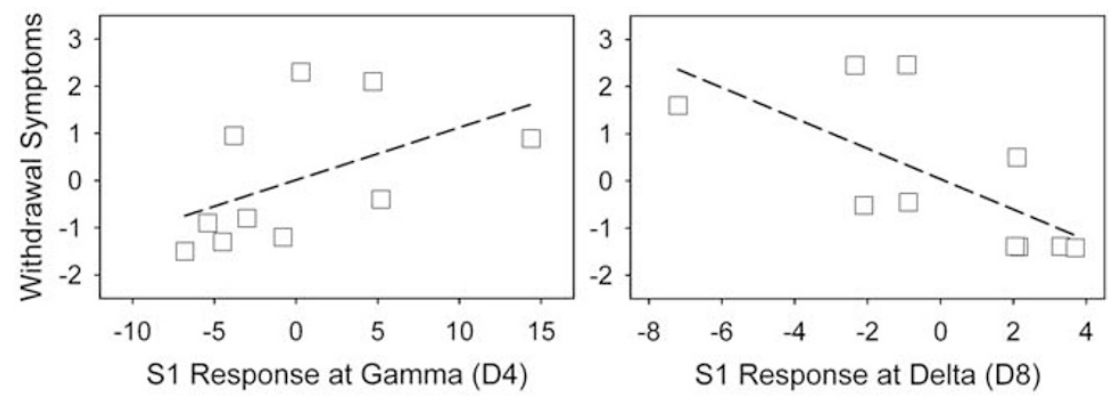

Figure 5 Contributions of gamma (D4, gamma) and low-frequency (D8, delta) interaction on BPRS withdrawal-retardation symptoms as shown by partial correlation graphs. Scales in graphs are residuals of the dependent variable (withdrawal symptoms) and the predictors (gamma, delta). The gamma $\times$ delta interaction term was significant $(p=0.020)$.

healthy controls (Krystal et al, 1994; Malhotra et al, 1996; Newcomer et al, 1999; Lahti et al, 2001) and worsen these symptoms in schizophrenia patients (Lahti et al, 1995, 2001; Malhotra et al, 1997), whereas its effects on BPRS hostility and mood symptoms were usually statistically insignificant (Malhotra et al, 1997; Lahti et al, 2001). This clinical profile was replicated in this sample (Table 1). Importantly, the withdrawal symptoms were significantly predicted by the gamma and low-frequency interaction: the withdrawal experience was positively correlated with $\mathrm{D} 4$ or gamma and negatively correlated with D8 or delta power during ketamine administration.

The following discussion focuses on whether the ketamine effect on oscillatory pattern mimics those observed in NMDA animal studies and abnormal oscillations in schizophrenia patients.

Increased gamma power by ketamine is a consistent finding in human (Plourde et al, 1997) and in vivo (anesthetized or awake) animal studies (Hunt et al, 2006; Pinault, 2008; Ehrlichman et al, 2009). In vitro studies initially described reduced gamma by ketamine (Cunningham et al, 2006; Zhang et al, 2008), although subsequent studies have refined this description by suggesting a regionally specific ketamine effect such that ketamine increases gamma at the primary auditory cortex but reduces or has no effect in other brain regions (Roopun et al, 2008). Therefore, the observed gamma augmentation at D4 $(40-85 \mathrm{~Hz})$ is consistent with prior observations. NMDA receptor antagonists increase the spontaneous firing rate of neurons in the medial PFC and nucleus accumbens (NAc) (Jackson et al, 2004; Hunt et al, 2008). Whether the effect on increased gamma observed in the human scalp is related to the corresponding rodent anatomical locations require further studies. We did not find significant ketamine effects on the low range of gamma $(20-40 \mathrm{~Hz})$. One study reported that general anesthetic dose $(2 \mathrm{mg} / \mathrm{kg})$ ketamine did not change $30-40 \mathrm{~Hz}$ power in response to auditory click in humans (Schwender et al, 1993).

Whether the increased gamma by ketamine is mimicking schizophrenia is less clear. As discussed in the Introduction, although most studies have shown a gamma band reduction in schizophrenia, increased gamma band in schizophrenia has also been shown. Previous data also showed that gamma band is positively correlated to the severity of psychosis (Spencer et al, 2004). Our finding suggests that ketamineinduced gamma augmentation, or rather a 'theta-to-gamma shift' (Ehrlichman et al, 2009), is positively correlated to the severity of withdrawal symptoms. However, it should be cautioned that the psychotomimetic withdrawal-retardation symptoms reported under acute ketamine may not be equivalent to negative symptoms in schizophrenia, because these symptoms occur while the person may be simply more occupied by internal subjective experience rather than a true avolitional pathology.

Although ketamine induces NMDA receptor hypofunction, acute ketamine leads to increased glutamate in the extracellular space in animals (Moghaddam et al, 1997) and increased glutamate in humans as measured by magnetic resonance spectroscopy (Rowland et al, 2005). Glutamate level is reduced in chronic schizophrenia (Theberge et al, 2003; Ohrmann et al, 2005, 2007) but increased in early psychosis (Theberge et al, 2002; Bartha et al, 1997). In parallel, gamma is often reported to be reduced in chronic schizophrenia, although increased gamma is found in early psychosis (Flynn et al, 2008). NMDA receptor blockade may cause hyperexcitation of glutamatergic neurons by disinhibition of GABAergic interneurons (Homayoun and Moghaddam, 2007). Perhaps, a mild shift in the excitation/inhibition balance toward excitation could result in gamma augmentation observed under subanesthetic ketamine. Taken together, we speculate that the augmented gamma indexes an increased glutamate secondary to NMDA antagonism. Further animal and clinical studies are required to investigate this possibility.

The finding of ketamine-induced theta-alpha and delta reduction is also consistent with the animal literature: NMDA and glutamate infusions augment hippocampal delta, theta, and alpha oscillations (Bonansco and Buno, 2003; Bland et al, 2007; Carre and Harley, 2000), whereas NMDA antagonists attenuate the augmentation effect (Bland et al, 2007). Delta-range oscillations are shown to correlate with the NAc neuron membrane potential changes (O'Donnell and Grace, 1995). NMDA antagonist reduces NAc delta power (Hunt et al, 2009) and induces glutamate release in NAc (Razoux et al, 2007). It has been suggested that this ketamine effect in NAc may mediate a psychoticlike effect of ketamine through the potentiation of synaptic efficacy in the prefrontal cortex-accumbens pathway (Razoux et al, 2007). It would be interesting to investigate whether this mechanism could explain a correlation between reduced delta and more ketamine-induced withdrawal symptoms. Importantly, the seemingly analogous 
pattern of ketamine effects on gamma and low frequencies between rodents and humans is encouraging because it provides an opportunity to study the NMDA mechanisms in schizophrenia in translational preclinical-clinical studies using oscillations as intermediate bioassays.

Subanesthetic ketamine appears to mimic some but not all aspects of sensory gating deficits in schizophrenia. Ketamine significantly reduced single-trial-based thetaalpha gating. This replicated the same finding in schizophrenia patients under essentially the same data processing methods (Hong et al, 2008b), which showed that patients and their non-ill first-degree relatives have significantly reduced theta-alpha gating while the reduction of P50 gating was not significant. The question of whether sensory gating is under the control of NMDA receptors has been evaluated. The lack of ketamine effect on AEP-based P50 is a replication of previous reports, all of which showed that ketamine itself did not significantly affect P50 gating in humans (van Berckel et al, 1998; Oranje et al, 2002). Animal studies suggest that ketamine has either no effect (de Bruin et al, 1999) or even increase in P20/N40 (the rodent AEP component believed to be equivalent to human P50) (Connolly et al, 2004). The negative findings can be due to a lack of significant NMDA receptor involvement in sensory gating, insufficient dose of ketamine, or methodology issues. We observed much similarity between ketamine and schizophrenia on gating of theta-alpha oscillation, indicating that the negative AEP-based findings may in part be due to insensitive methodology.

This observation would suggest that sensory gating problems observed in schizophrenia might in part be associated with a NMDA receptor deficit or antagonism. However, we also observed one distinct difference: the reduced theta-alpha gating in schizophrenia patients was observed on the background of elevated theta-alpha oscillations compared with healthy controls (Hong et al, 2008b; Figure 2). Here, we observed an opposite effect such that ketamine reduced low-frequency oscillations. The reason for this contradiction is not known and may seem at odd with the finding of similar theta-alpha gating deficit between schizophrenia and ketamine challenge. However, acute ketamine does not necessarily mimic all aspects of schizophrenia. Acute ketamine in similar dose and study design has also generated an opposite effect on prepulse inhibition compared with that in schizophrenia, by increasing rather than decreasing prepulse inhibition (Abel et al, 2003).

To summarize, glutamatergic receptors are integral components of current theories on rhythmatogenesis (Cunningham et al, 2006; Gonzalez-Burgos and Lewis, 2008; Roopun et al, 2008) and may also be associated with abnormal electrical brain oscillations in schizophrenia. We observed that acute ketamine affects both gamma and lowfrequency bands in humans, which mimic some aspects of the oscillatory pattern observed in schizophrenia. Our finding also suggests that the ketamine-induced gamma/ delta reversal seen in animal studies (Ehrlichman et al, 2009) maybe indexing some aspects of schizophrenia-like symptoms. Given the small sample size, our study might have missed some other important electrophysiologyclinical correlates. Overall, this study illustrates the potentials of using frequency-based neural oscillations to complement and, in some cases, to replace AEP for animalclinical translational studies.

\section{ACKNOWLEDGEMENTS}

The study was supported by the National Institute on Health grants MH70644, 79172, 49826, 77852, and 68580.

\section{DISCLOSURE}

The authors declare no conflict of interest.

\section{REFERENCES}

Abel KM, Allin MP, Hemsley DR, Geyer MA (2003). Low dose ketamine increases prepulse inhibition in healthy men. Neuropharmacology 44: 729-737.

Amann LC, Halene TB, Ehrlichman RS, Luminais SN, Ma N, Abel T et al (2009). Chronic ketamine impairs fear conditioning and produces long-lasting reductions in auditory evoked potentials. Neurobiol Dis 35: 311-317.

Arnfred SM, Chen AC, Glenthoj BY, Hemmingsen RP (2003). Normal p50 gating in unmedicated schizophrenia outpatients. Am J Psychiatry 160: 2236-2238.

Bartha R, Williamson PC, Drost DJ, Malla A, Carr TJ, Cortese L et al (1997). Measurement of glutamate and glutamine in the medial prefrontal cortex of never-treated schizophrenic patients and healthy controls by proton magnetic resonance spectroscopy. Arch Gen Psychiatry 54: 959-965.

Basar-Eroglu C, Brand A, Hildebrandt H, Karolina KK, Mathes B, Schmiedt C (2007). Working memory related gamma oscillations in schizophrenia patients. Int J Psychophysiol 64: 39-45.

Bland BH, Declerck S, Jackson J, Glasgow S, Oddie S (2007). Septohippocampal properties of $\mathrm{N}$-methyl-D-aspartate-induced theta-band oscillation and synchrony. Synapse 61: 185-197.

Boeijinga PH, Soufflet L, Santoro F, Luthringer R (2007). Ketamine effects on CNS responses assessed with MEG/EEG in a passive auditory sensory-gating paradigm: an attempt for modelling some symptoms of psychosis in man. J Psychopharmacol 21: 321-337.

Bonansco C, Buno W (2003). Cellular mechanisms underlying the rhythmic bursts induced by NMDA microiontophoresis at the apical dendrites of CA1 pyramidal neurons. Hippocampus 13: 150-163.

Bremner JD, Krystal JH, Putnam FW, Southwick SM, Marmar C, Charney DS et al (1998). Measurement of dissociative states with the Clinician-Administered Dissociative States Scale (CADSS). J Trauma Stress 11: 125-136.

Brockhaus-Dumke A, Mueller R, Faigle U, Klosterkoetter J (2008). Sensory gating revisited: relation between brain oscillations and auditory evoked potentials in schizophrenia. Schizophr Res 99: 238-249.

Carre GP, Harley CW (2000). Glutamatergic activation of the medial septum complex: an enhancement of the dentate gyrus population spike and accompanying EEG and unit changes. Brain Res 861: 16-25.

Cho RY, Konecky RO, Carter CS (2006). Impairments in frontal cortical gamma synchrony and cognitive control in schizophrenia. Proc Natl Acad Sci USA 103: 19878-19883.

Clementz BA, Geyer MA, Braff DL (1998). Poor P50 suppression among schizophrenia patients and their first-degree biological relatives. Am J Psychiatry 155: 1691-1694.

Clementz BA, Sponheim SR, Iacono WG, Beiser M (1994). Resting EEG in first-episode schizophrenia patients, bipolar psychosis patients, and their first-degree relatives. Psychophysiology 31: 486-494. 
Connolly PM, Maxwell C, Liang Y, Kahn JB, Kanes SJ, Abel T et al (2004). The effects of ketamine vary among inbred mouse strains and mimic schizophrenia for the P80, but not P20 or N40 auditory ERP components. Neurochem Res 29: 1179-1188.

Coyle JT (1996). The glutamatergic dysfunction hypothesis for schizophrenia. Harv Rev Psychiatry 3: 241-253.

Cunningham MO, Hunt J, Middleton S, LeBeau FE, Gillies MJ, Davies $\mathrm{CH}$ et al (2006). Region-specific reduction in entorhinal gamma oscillations and parvalbumin-immunoreactive neurons in animal models of psychiatric illness. J Neurosci 26: 2767-2776. de Bruin NM, Ellenbroek BA, Cools AR, Coenen AM, van Luijtelaar EL (1999). Differential effects of ketamine on gating of auditory evoked potentials and prepulse inhibition in rats. Psychopharmacology (Berl) 142: 9-17.

de Wilde OM, Bour LJ, Dingemans PM, Koelman JH, Linszen DH (2007). Failure to find P50 suppression deficits in young firstepisode patients with schizophrenia and clinically unaffected siblings. Schizophr Bull 33: 1319-1323.

Ehrlichman RS, Gandal MJ, Maxwell CR, Lazarewicz MT, Finkel LH, Contreras D et al (2009). $N$-methyl-D-aspartic acid receptor antagonist-induced frequency oscillations in mice recreate pattern of electrophysiological deficits in schizophrenia. Neuroscience 158: 705-712.

Flynn G, Alexander D, Harris A, Whitford T, Wong W, Galletly C et al (2008). Increased absolute magnitude of gamma synchrony in first-episode psychosis. Schizophr Res 105: 262-271.

Freedman R, Coon H, Myles-Worsley M, Orr-Urtreger A, Olincy A, Davis A et al (1997). Linkage of a neurophysiological deficit in schizophrenia to a chromosome 15 locus. Proc Natl Acad Sci USA 94: 587-592.

Gallinat J, Winterer G, Herrmann CS, Senkowski D (2004). Reduced oscillatory gamma-band responses in unmedicated schizophrenic patients indicate impaired frontal network processing. Clin Neurophysiol 115: 1863-1874.

Gonzalez-Burgos G, Lewis DA (2008). GABA neurons and the mechanisms of network oscillations: implications for understanding cortical dysfunction in schizophrenia. Schizophr Bull 34: 944-961.

Hedlund JL, Vieweg BW (1980). The brief psychiatric rating scale (BPRS): a comprehensive review. J Operational Psychiatry 11: $48-64$.

Heresco-Levy U, Javitt DC (1998). The role of $N$-methyl-Daspartate (NMDA) receptor-mediated neurotransmission in the pathophysiology and therapeutics of psychiatric syndromes. Eur Neuropsychopharmacol 8: 141-152.

Homayoun H, Moghaddam B (2007). NMDA receptor hypofunction produces opposite effects on prefrontal cortex interneurons and pyramidal neurons. J Neurosci 27: 11496-11500.

Hong LE, Buchanan RW, Thaker GK, Shepard PD, Summerfelt A (2008a). Beta (approximately $16 \mathrm{~Hz}$ ) frequency neural oscillations mediate auditory sensory gating in humans. Psychophysiology 45: 197-204.

Hong LE, Summerfelt A, Mitchell BD, McMahon RP, Wonodi I, Buchanan RW et al (2008b). Sensory gating endophenotype based on its neural oscillatory pattern and heritability estimate. Arch Gen Psychiatry 9: 1008-1016.

Hunt M, Falinska M, Kasicki S (2009). Local injection of MK801 modifies oscillatory activity in the nucleus accumbens in awake rats. J Psychopharmacol (E-pub ahead of print).

Hunt MJ, Garcia R, Large CH, Kasicki S (2008). Modulation of high-frequency oscillations associated with NMDA receptor hypofunction in the rodent nucleus accumbens by lamotrigine. Prog Neuropsychopharmacol Biol Psychiatry 32: 1312-1319.

Hunt MJ, Raynaud B, Garcia R (2006). Ketamine dose-dependently induces high-frequency oscillations in the nucleus accumbens in freely moving rats. Biol Psychiatry 60: 1206-1214.

Jackson ME, Homayoun H, Moghaddam B (2004). NMDA receptor hypofunction produces concomitant firing rate potentiation and burst activity reduction in the prefrontal cortex. Proc Natl Acad Sci USA 101: 8467-8472.

Karson CN, Coppola R, Daniel DG, Weinberger DR (1988). Computerized EEG in schizophrenia. Schizophr Bull 14: 193-197.

Kathmann N, Engel RR (1990). Sensory gating in normals and schizophrenics: a failure to find strong P50 suppression in normals. Biol Psychiatry 27: 1216-1226.

Kay SM (1988). Modern Spectral Estimation: Theory and Application. Prentice Hall: Englewood Cliffs, NJ.

Keshavan MS, Rosenberg D, Sweeney JA, Pettegrew JW (1998). Decreased caudate volume in neuroleptic-naive psychotic patients. Am J Psychiatry 155: 774-778.

Kissler J, Muller MM, Fehr T, Rockstroh B, Elbert T (2000). MEG gamma band activity in schizophrenia patients and healthy subjects in a mental arithmetic task and at rest. Clin Neurophysiol 111: 2079-2087.

Knott V, Labelle A, Jones B, Mahoney C (2001). Quantitative EEG in schizophrenia and in response to acute and chronic clozapine treatment. Schizophr Res 50: 41-53.

Krystal JH, D'Souza DC, Petrakis IL, Belger A, Berman RM, Charney DS et al (1999). NMDA agonists and antagonists as probes of glutamatergic dysfunction and pharmacotherapies in neuropsychiatric disorders. Harv Rev Psychiatry 7: 125-143.

Krystal JH, Karper LP, Seibyl JP, Freeman GK, Delaney R, Bremner $\mathrm{D}$ et al (1994). Subanesthetic effects of the noncompetitive NMDA antagonist, ketamine, in humans: psychotomimetic, perceptual, cognitive, and neuroendocrine responses. Arch Gen Psychiatry 51: 199-214.

Kwon JS, O'Donnell BF, Wallenstein GV, Greene RW, Hirayasu Y, Nestor PG et al (1999). Gamma frequency-range abnormalities to auditory stimulation in schizophrenia. Arch Gen Psychiatry 56: 1001-1005.

Lahti AC, Holcomb HH, Medoff DR, Tamminga CA (1995). Ketamine activates psychosis and alters limbic blood flow in schizophrenia. NeuroReport 6: 869-872.

Lahti AC, Weiler MA, Tamara Michaelidis BA, Parwani A, Tamminga CA (2001). Effects of ketamine in normal and schizophrenic volunteers. Neuropsychopharmacology 25: 455467.

Lahti RA, Tamminga CA (1999). Effect of amphetamine, alphamethyl-p-tyrosine (alpha-MPT) and antipsychotic agents on dopamine D2-type receptor occupancy in rats. Prog Neuropsychopharmacol Biol Psychiatry 23: 1277-1283.

Lazarewicz MT, Ehrlichman RS, Maxwell CR, Gandal MJ, Finkel LH, Siegel SJ (2009). Ketamine modulates theta and gamma oscillations. J Cogn Neurosci (E-pub ahead of print).

Lee KH, Williams LM, Haig A, Goldberg E, Gordon E (2001). An integration of $40 \mathrm{~Hz}$ gamma and phasic arousal: novelty and routinization processing in schizophrenia. Clin Neurophysiol 112: 1499-1507.

Malhotra AK, Pinals DA, Adler CM, Elman I, Clifton A, Pickar D et al (1997). Ketamine-induced exacerbation of psychotic symptoms and cognitive impairment in neuroleptic-free schizophrenics. Neuropsychopharmacology 17: 141-150.

Malhotra AK, Pinals DA, Weingartner H, Sirocco K, Missar CD, Pickar D et al (1996). NMDA receptor function and human cognition: the effects of ketamine in healthy volunteers. Neuropsychopharmacology 14: 301-307.

Meador-Woodruff JH, Healy DJ (2000). Glutamate receptor expression in schizophrenic brain. Brain Res Brain Res Rev 31: 288-294.

Moghaddam B, Adams B, Verma A, Daly D (1997). Activation of glutamatergic neurotransmission by ketamine: a novel step in the pathway from NMDA receptor blockade to dopaminergic and cognitive disruptions associated with the prefrontal cortex. J Neurosci 17: 2921-2927. 
Myles-Worsley M (2002). P50 sensory gating in multiplex schizophrenia families from a Pacific island isolate. $A m \mathrm{~J}$ Psychiatry 159: 2007-2012.

Nagamoto HT, Adler LE, Waldo MC, Freedman R (1989). Sensory gating in schizophrenics and normal controls: effects of changing stimulation interval. Biol Psychiatry 25: 549-561.

Nagase Y, Okubo Y, Matsuura M, Kojima T, Toru M (1992). EEG coherence in unmedicated schizophrenic patients: topographical study of predominantly never medicated cases. Biol Psychiatry 32: 1028-1034.

Newcomer JW, Farber NB, Jevtovic-Todorovic V, Selke G, Melson AK, Hershey $\mathrm{T}$ et al (1999). Ketamine-induced NMDA receptor hypofunction as a model of memory impairment and psychosis. Neuropsychopharmacology 20: 106-118.

Norra C, Waberski TD, Kawohl W, Kunert HJ, Hock D, Gobbele R et al (2004). High-frequency somatosensory thalamocortical oscillations and psychopathology in schizophrenia. Neuropsychobiology 49: 71-80.

O’Donnell P, Grace AA (1995). Synaptic interactions among excitatory afferents to nucleus accumbens neurons: hippocampal gating of prefrontal cortical input. J Neurosci 15: 3622-3639.

Ohrmann P, Siegmund A, Suslow T, Pedersen A, Spitzberg K, Kersting A et al (2007). Cognitive impairment and in vivo metabolites in first-episode neuroleptic-naive and chronic medicated schizophrenic patients: a proton magnetic resonance spectroscopy study. J Psychiatr Res 41: 625-634.

Ohrmann P, Siegmund A, Suslow T, Spitzberg K, Kersting A, Arolt $\mathrm{V}$ et al (2005). Evidence for glutamatergic neuronal dysfunction in the prefrontal cortex in chronic but not in first-episode patients with schizophrenia: a proton magnetic resonance spectroscopy study. Schizophr Res 73: 153-157.

Omori M, Koshino Y, Murata T, Murata I, Nishio M, Sakamoto K et al (1995). Quantitative EEG in never-treated schizophrenic patients. Biol Psychiatry 38: 305-309.

Oranje B, Gispen-de Wied CC, Verbaten MN, Kahn RS (2002). Modulating sensory gating in healthy volunteers: the effects of ketamine and haloperidol. Biol Psychiatry 52: 887-895.

Pinault D (2008). $N$-methyl-D-aspartate receptor antagonists ketamine and MK-801 induce wake-related aberrant gamma oscillations in the rat neocortex. Biol Psychiatry 63: 730-735.

Plourde G, Baribeau J, Bonhomme V (1997). Ketamine increases the amplitude of the $40-\mathrm{Hz}$ auditory steady-state response in humans. Br J Anaesth 78: 524-529.

Razoux F, Garcia R, Lena I (2007). Ketamine, at a dose that disrupts motor behavior and latent inhibition, enhances prefrontal cortex synaptic efficacy and glutamate release in the nucleus accumbens. Neuropsychopharmacology 32: 719-727.

Roopun AK, Cunningham MO, Racca C, Alter K, Traub RD, Whittington MA (2008). Region-specific changes in gamma and beta2 rhythms in NMDA receptor dysfunction models of schizophrenia. Schizophr Bull 34: 962-973.

Rowland LM, Bustillo JR, Mullins PG, Jung RE, Lenroot R, Landgraf $\mathrm{E}$ et al (2005). Effects of ketamine on anterior cingulate glutamate metabolism in healthy humans: a 4 -T proton MRS study. Am J Psychiatry 162: 394-396.

Sanchez-Morla EM, Garcia-Jimenez MA, Barabash A, MartinezVizcaino V, Mena J, Cabranes-Diaz JA et al (2008). P50 sensory gating deficit is a common marker of vulnerability to bipolar disorder and schizophrenia. Acta Psychiatr Scand 117: 313-318.

Schwender D, Klasing S, Madler C, Poppel E, Peter K (1993). Midlatency auditory evoked potentials during ketamine anaesthesia in humans. Br J Anaesth 71: 629-632.

Shepard PD, Joy B, Clerkin L, Schwarcz R (2003). Micromolar brain levels of kynurenic acid are associated with a disruption of auditory sensory gating in the rat. Neuropsychopharmacology 28: $1454-1462$.

Siegel C, Waldo M, Mizner G, Adler LE, Freedman R (1984). Deficits in sensory gating in schizophrenic patients and their relatives. Evidence obtained with auditory evoked responses. Arch Gen Psychiatry 41: 607-612.

Spencer KM, Nestor PG, Perlmutter R, Niznikiewicz MA, Klump MC, Frumin M et al (2004). Neural synchrony indexes disordered perception and cognition in schizophrenia. Proc Natl Acad Sci USA 101: 17288-17293.

Sponheim SR, Clementz BA, Iacono WG, Beiser M (1994). Resting EEG in first-episode and chronic schizophrenia. Psychophysiology 31: 37-43.

Sponheim SR, Iacono WG, Thuras PD, Nugent SM, Beiser M (2003). Sensitivity and specificity of select biological indices in characterizing psychotic patients and their relatives. Schizophr Res 63: 27-38.

Symond MP, Harris AW, Gordon E, Williams LM (2005). 'Gamma synchrony' in first-episode schizophrenia: a disorder of temporal connectivity? Am J Psychiatry 162: 459-465.

Tauscher J, Fischer P, Neumeister A, Rappelsberger P, Kasper S (1998). Low frontal electroencephalographic coherence in neuroleptic-free schizophrenic patients. Biol Psychiatry 44: 438-447.

Theberge J, Al Semaan Y, Williamson PC, Menon RS, Neufeld RW, Rajakumar $\mathrm{N}$ et al (2003). Glutamate and glutamine in the anterior cingulate and thalamus of medicated patients with chronic schizophrenia and healthy comparison subjects measured with 4.0-T proton MRS. Am J Psychiatry 160: 2231-2233.

Theberge J, Bartha R, Drost DJ, Menon RS, Malla A, Takhar J et al (2002). Glutamate and glutamine measured with $4.0 \mathrm{~T}$ proton MRS in never-treated patients with schizophrenia and healthy volunteers. Am J Psychiatry 159: 1944-1946.

Traub RD, Whittington MA, Buhl EH, Jefferys JG, Faulkner HJ (1999). On the mechanism of the gamma $\rightarrow$ beta frequency shift in neuronal oscillations induced in rat hippocampal slices by tetanic stimulation. J Neurosci 19: 1088-1105.

van Berckel BN, Oranje B, van Ree JM, Verbaten MN, Kahn RS (1998). The effects of low dose ketamine on sensory gating, neuroendocrine secretion and behavior in healthy human subjects. Psychopharmacology (Berl) 137: 271-281.

Welch PD (1967). The use of fast Fourier transform for estimation of power spectra: a method based on time averaging over short, modified periodograms. IEEE Trans on Audio Electroacoustics AU-15: 70-73.

Whittington MA, Traub RD, Jefferys JG (1995). Synchronized oscillations in interneuron networks driven by metabotropic glutamate receptor activation. Nature 373: 612-615.

Zhang Y, Behrens MM, Lisman JE (2008). Prolonged exposure to NMDAR antagonist suppresses inhibitory synaptic transmission in prefrontal cortex. J Neurophysiol 100: 959-965. 